\title{
BANIWA YAVITENSIS LICHY, 1981 (LEPIDOPTERA: SPHINGIDAE) NA AMAZÔNIA BRASILEIRA ${ }^{1}$
}

\section{Catarina da Silva MOTTA ${ }^{2}$, Alexandre SOARES ${ }^{3}$}

RESUMO - O trabalho documenta o primeiro registro de uma fêmea de Baniwa yavitensis Líchy, 1981, para os Estados do Amazonas e do Pará, Brasil. A genitália da fềmea é descrita e a do macho redescrita.

Palavras chave: Baniwa yavitensis, Lepidoptera: Sphingidae, Taxonomia, Amazônia brasileira.

Baniwa yavitensis Lichy, 1981 (Lepidoptera: Sphingidae) in the Brazilian Amazon

ABSTRACT - The first known female and a male of Baniwa yavitensis Lichy, 1981 are described, including their genitalia, respectively from Amazonas and Pará State, Brazil.

Key words: Baniwa yavitensis, Lepidoptera: Sphingidae, Taxonomy, Brazilian Amazon.

\section{INTRODUÇÃO}

LICHY (1981) descreve Baniwa yavitensis (Lepidoptera: Sphingoidea: Sphingidae: Macroglossinae: Dilophonotini) baseando-se em quatro exemplares machos, provenientes de Yavita, Territorio Federal Amazonas, Venezuela. D'ABRERA (1986) apresenta uma fotografia de Philipe Darge (Paris - França) do espécime tipo macho, no apêndice de seu livro. CHACIN \& CLAVIJO (1995) assinalam que este gênero apresenta uma distribuição restrita ao Amazonas venezuelano e listam três exemplares, dentre estes um parátipo de Lichy. MOTTA \& SOARES (1996) apresentaram, uma comunicação breve, em Congresso, no Rio de Janeiro, RJ; o desenvolvimento desta nota resultou no presente trabalho. Até o presente momento esta espécie era considerada endêmica da região amazônica, no Estado Amazonas, Venezuela. Registra-se mais dois exemplares, uma fêmea e um macho, provenientes respectivamente dos Estados do Amazonas e do Pará, no Brasil. Este é o primeiro registro da fêmea desta espécie de gênero monotípico. Apresenta-se a descrição da fêmea e redescrição do macho, tendo como base as genitálias.

\section{MATERIAL E MÉTODOS}

Os dois exemplares utilizados neste trabalho tềm os seguintes dados, de acordo com suas etiquetas: Fêmea - $1^{\text {a }}$ etiq.: BR AM Pq Nac. do Jaú; Ig. Miratuca ( = Brasil; Amazonas; Parque Nacional do Jaú; igarapé Miratuca); 20 21/VII/1993; 157'08”'S/6149'19”'W; Andreazze, R., Costa, W. \& Aquino, L. col. $2^{\text {a }}$ etiq.: Lençol com luz mista de mercúrio, luz negra BL e BLB. $3^{\mathrm{a}}$ etiq.:

Projeto "Levantamento da Entomofauna do Parque Nacional do Jaú" - INPA, 1993 - 1994 em Convênio com a Fundação Vitoria Amazonica/Manaus-AM.

2 Coordenação de Pesquisas em Entomologia (CPEN), Instituto Nacional de Pesquisas da Amazônia (INPA), Caixa Postal 478, 69011-970 Manaus, AM, Brasil.

3 Depto. de Entomologia, Museu Nacional do Rio de Janeiro (MNRJ), Universidade Federal do Rio de Janeiro (UFRJ), Quinta da Boa Vista, , São Cristovão, 20940-040, Rio de Janeiro, RJ, Brasil. 
20:00 às 21:00h. $4^{\text {a }}$ etiq.: Baniwa yavitensis Lichy, 1981; fềmea; 13/IX/1993 Motta, C.S. det. $5^{a}$ etiq. 20/VII/1993 - Lua Minguante; 21/VII/1993 -Lua Nova. $6^{\text {a }}$ etiq.: 11007 ( $\mathrm{n}^{\mathrm{o}}$ do INPA). Macho - $1^{\mathrm{a}}$ etiq.: Cachimbo (E. Pará); Travassos - Oliveira \& Adão; 25/9-10/956. $2^{\mathrm{a}}$ etiq.: P.A.S. ( = Preparação de Alexandre Soares). $3^{\text {a }}$ etiq. Baniwa yavitensis Lichy, 1981; macho; A. Soares det. 1986. Quanto às etiquetas do exemplar macho, parece-nos, de acordo com TRAVASSOS (1957): 25/ $9=$ que $o$ exemplar foi coletado entre os dias 25 e $29 ; 10=$ outubro; $956=1956$; por Lauro Travassos, Sebastião J. Oliveira \& Adão; no Brasil, Estado do Pará, na serra do Cachimbo.

As asas foram medidas do meio da base até o ápice. As preparações das genitálias, para desenho sob microscópio estereoscópico, seguiram as técnicas usuais. A fềmea encontra-se depositada na Coleção de Invertebrados (Col. Entomológica) do Instituto Nacional de Pesquisas da Amazônia - INPA e o macho na Coleção Entomológica do Instituto Oswaldo Cruz - IOC.

Para a identificação destas mariposas foram utilizados LICHY (1981) e D'ABRERA (1986); a classificação segue HODGES (1971) e quanto às descrições das genitálias a nomenclatura seguida foi a de KLOTS in TUXEN (1970).

\section{RESULTADOS}

Baniwa yavitensis Lichy, 1981

Macho e fềmea sem dimorfismo sexual, o padrão de colorido é muito semelhante quando comparado com a descrição primorosa de LICHY (1981).

Fêmea (Fig. 1) - Vistas dorsal e ventral: Cabeça, tórax, asas e abdome com o mesmo padrão de colorido do macho. A espiritromba com $21 \mathrm{~mm}$. Asa anterior com $27 \mathrm{~mm}$,

Genitália (Fig. 2) - Vista ventral: Papilas anais em número de quatro

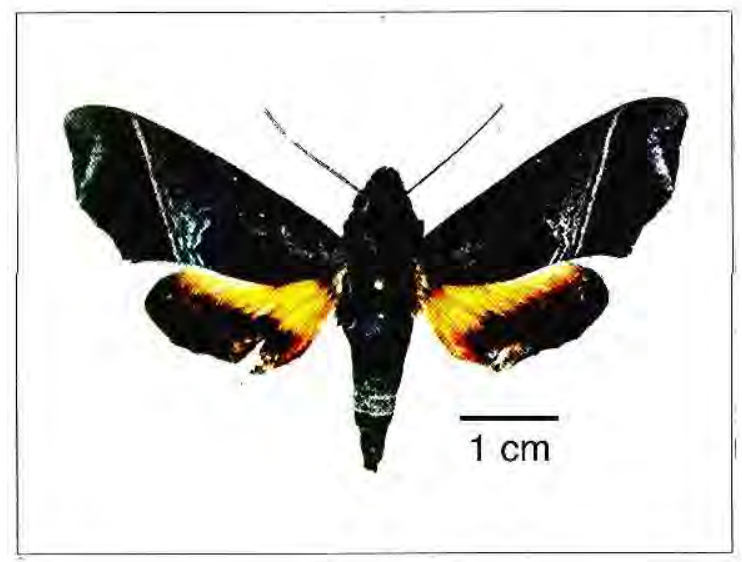

Figura 1. Baniwa yavitensis Lichy, 1981, vista dorsal da fêmea. Exemplar n⿳⺈ 11007 da Coleção de Invertebrados do INPA. 


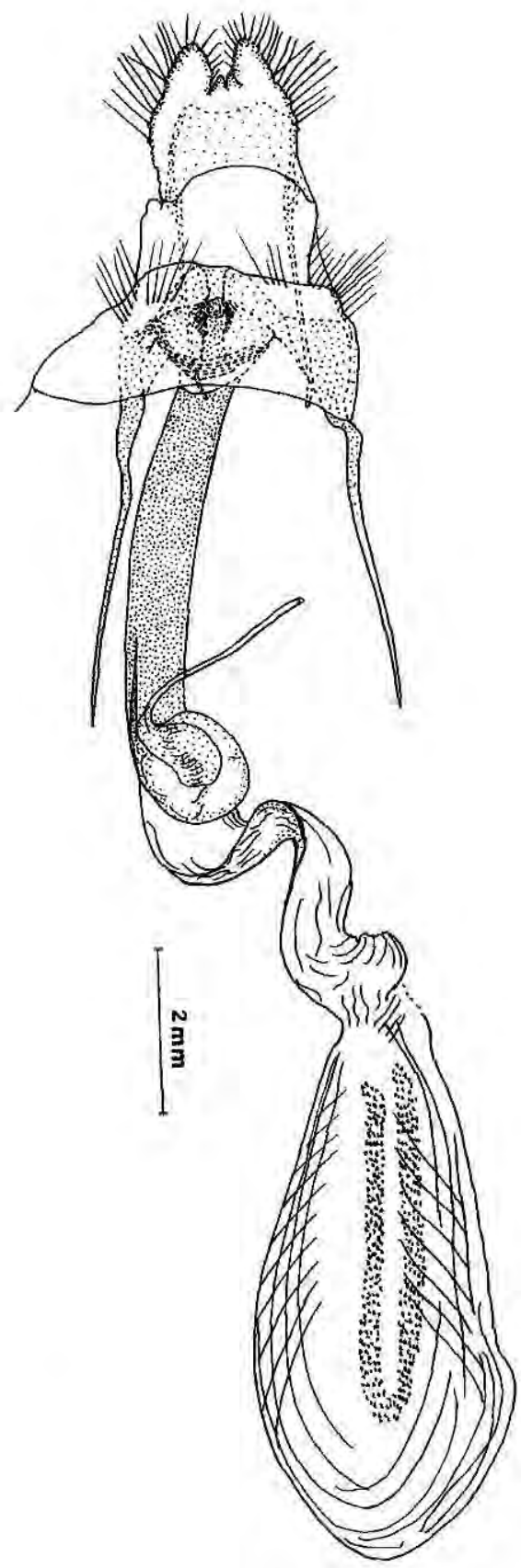

Figura 2. Baniwa yavitensis Lichy, 1981 - Genitália feminina: vista ventral. Exemplar $n^{\circ} 11007$ da Coleção de Invertebrados do INPA. 
sendo duas maiores e duas menores. Apófises posteriores terminando em pontas rombas e apófises anteriores terminando em pontas agudas. Duto seminal encontra-se na parte posterior menos esclerosada do duto da bolsa, próximo ao antro. Esterigma subelíptico e pouco esclerosado. Óstio arredondado, bem esclerosado. Duto da bolsa com antro bem esclerosado compreendendo cerca de $1 / 3$ de todo o duto da bolsa. Bolsa claviforme, apresenta signo bem desenvolvido com dentículos esclerosados, dispostos em duas fileiras semi-paralelas.

Macho - Espiritromba de $22 \mathrm{~mm}$. A asa anterior medindo $27 \mathrm{~mm}$.

Genitalia (Fig. 3) - Vista ventral: $10^{\circ}$ tergito: uncus bífido, apontado para a parte terminal do abdome, terminando em pontas afiladas. $10^{\circ}$ esternito: gnato bífido com as extremidades bifurcadas pontiagudas, de tamanhos desiguais, duas maiores e duas menores. Valvas subiguais com a extremidade distal alargada, em forma de espátula sublosangular; na costa (extremidade dorso-proximal) apresenta um lobo de ponta arredondada (processo basal da costa), voltado para a parte interna; tanto as valvas quanto seus lobos são densamente cobertos de cerdas. Sáculo bem desenvolvido continuado pelos processo do saco bastante afilados, assimétricos e curvados para dentro. Juxta subtriangular. Edeago (Fig. 4) cilíndrico, bem esclerosado, com a extremidade terminal fortemente curva, em forma de bengala, apresentando no

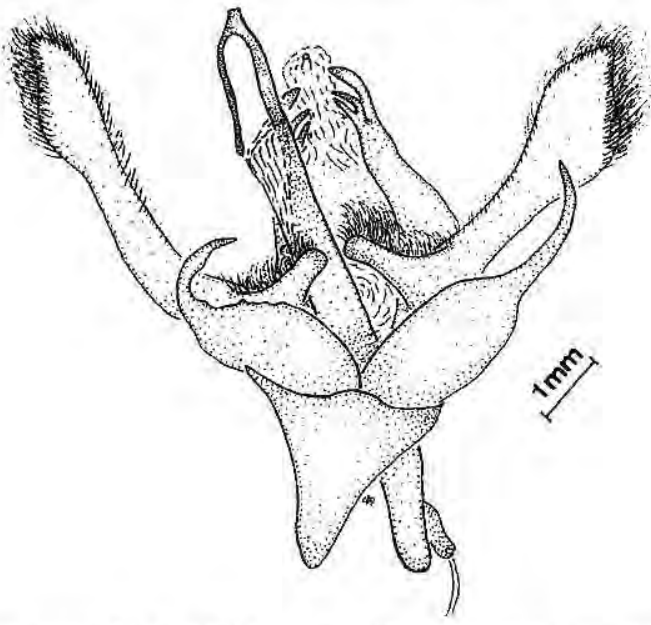

Figura 3. Baniwa yavitensis Lichy, 1981 - Genitália masculina. vista ventral.

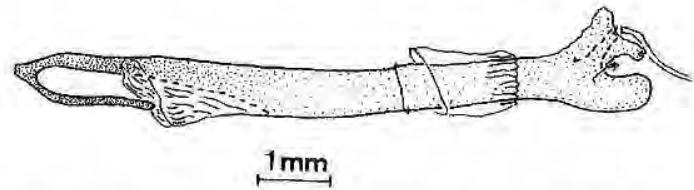

Figura 4. Edeago, vista lateral. Exemplar da Coleção Entomológica do IOC. 
meio da curva um lóbulo com ponta romba. Durante a dissecção e preparação a vesica não ficou totalmente evertida.

\section{Considerações finais}

Desta espécie são poucos os exemplares depositados em coleções científicas. Embora tenha-se realizado inúmeras expedições científicas, dentro da Amazônia brasileira, a Coleção do INPA só possui o espécime fềmea aqui descrito e o IOC um macho.

As coordenadas dos locais onde foram coletados Baniwa yavitensis são respectivamente: Yavita (Venezuela) $02^{\circ} 55^{\prime}$ N $/ 67^{\circ} 26^{\prime} \mathrm{W}$; Parque Nacional do Jaú (Brasil) - 0157'08'S/6549'19'W e Serra do Cachimbo (Brasil) $08^{\circ} 30^{\prime} \mathrm{S} / 55^{\circ} 50^{\prime} \mathrm{W}$. As distâncias aproximadas, em linha reta, são: do Parque Nacional do Jaú (Ig. Miratuca) até Yavita $(\mathrm{VE})=$ cerca de $1000 \mathrm{~km}$; de S. Cachimbo até o P. N. Jaú = cerca de $1200 \mathrm{~km}$ e de S. Cachimbo até Yavita $=$ cerca de $2200 \mathrm{~km}$. Conclui-se que esta espécie, até o presente momento, tem sua área de endemismo neotropical, alcançando a Amazônia brasileira e venezuelana. Porém não se descarta a hipótese destes resultados estarem ligados à falta de coletas.

\section{AGRADECIMENTOS}

Agradecimentos especiais aos pesquisadores P. Cerdan (Guiana Francesa) que nos colocou em contato com o lepidopterologista Jean Haxaire (Paris - França) e tão gentilmente nos enviou cópia do trabalho de Lichy, 1981 e ao Dr. Sebastião J. de Oliveira, pelo empréstimo do material da Coleção Entomológica do IOC. Também somos gratos aos pesquisadores Ricardo Andreazze, Wellington L. Costa e ao técnico Luiz S. de Aquino, que na impossibilidade de um dos autores (CSM) ir na expedição científica, ao Parque Nacional do Jaú, ai estiveram e coletaram, durante 15 noites consecutivas, esta mariposa dentre as demais. Sphingidae.

\section{Bibliografia Citada}

D'ABRERA, B. 1986. Sphingidae Mundi (Hawk Moths of the World). E.W. Classey Ltd., Oxon, 226p.

CHACIN, M.E.; CLAVIJO, J.A. 1995. Sphingidae (Insecta: Lepidoptera) del Estado Amazonas, Venezuela. Bol. Entomol. Venez. N.S, 10(1):7-24.

HODGES, R.W. 1971. The Moths of America North of Mexico (Sphingoidea). Fasc. 21, E.W. Classey Ltd.; R.B.D. Publications Inc., London, 158+XIIp., 14pl.

KLOTS, A,B. 1970. In TUXEN, S.L. (ed.). Taxonomist's Glossary of Genitalia in Insects.. Copenhagen, 2nd. ed., :115-130.

LICHY, R. 1981. Documentos para el estudio de los Sphingidae de Venezuela. Bol. Entomol. Venez. N.S. 1 (5) :57-70.

TRAVASSOS, L. 1957. Contribuição ao conhecimento dos Arctiidae. XXXVII. Gênero "Castrica" Schaus, 1896 (Lepidoptera, Heterocera). Revista brasileira de Biologia 17 (2) : 227-234. 